\title{
EXAMINATION OF STRESS COPING STRATEGIES AS PREDICTORS OF ACADEMIC PERFORMANCE AMONG STUDENTS IN TEACHER TRAINING COLLEGES IN CENTRAL REGION KENYA
}

\author{
Elizabeth Ndinda Muema ${ }^{1}$ \\ ${ }^{1} \mathrm{PhD}$ student, \\ Department of Educational Psychology and \\ Special Needs Education Machakos University \\ P o Box 136-90100 \\ Machakos Kenya.
}

\author{
Prof James Muola ${ }^{2}$ \\ ${ }^{2}$ Department of Educational Psychology and \\ Special Needs Education Machakos University \\ P o Box 136-90100 \\ Machakos Kenya.
}

\author{
Dr Pamela Muriungi ${ }^{3}$ \\ ${ }^{3}$ Department of Educational Psychology and \\ Special Needs Education Machakos University \\ Po Box 136-90100. \\ Machakos Kenya
}

Article DOI: https://doi.org/10.36713/epra5145

\begin{abstract}
Despite the very high stake placed on education, poor academic performance has continued to be felt in Kenya in Primary Teacher Training colleges in Kenya. This affects the life and career progression of the students and becomes a challenge to both the parents and the nation at large. The study sought to establish how stress coping strategies predict academic performance among students in Primary Teacher Training Colleges in central region. Questionnaire on coping strategies was adapted from CISS-21 by endler and Parker. Academic Performance was inferred from the students mean grade obtained from the Mid-course examinations at the end of year one. Quantitative data was analyzed using SPSS version 26. To examine the relationships among the variables Pearson Product Moment Correlation Coefficient and regression analysis were used. Generally there was a negative significant correlation between the overall measure of Coping strategies $\quad r=0 .-56, p<0.01$, $n=197)$.Academic performance was found to be significantly correlated with a) task oriented coping at $(r=0.68, p<0.01$, $n=197), b)$ emotional oriented coping $(r=0 .-75, p,<0.01)$ and $c)$ avoidance oriented coping $(r=0 .-68, p,<0.01) .0 n$ regression analysis, Coping strategies had a significant predictive weight on academic performance $(F, 1,195)=89.5, p<0.0)$ with use of emotion and avoidance coping significantly predicting academic performance. Based on the findings it was recommended that educators, lecturers and other education stakeholders should create an enabling environment in order to enhance students' academic self-efficacy, response to stressful situations and coping strategies. Students support services like guidance and counselling should be strengthened, and is important for the colleges to have intervention programs to buffer the negative impact of stressful environments and enhance positive coping strategies.

KEY WORDS: Coping Strategies, Task oriented, Emotion oriented, Avoidance oriented, Performance, Teacher Training Colleges,
\end{abstract}




\section{BACKGROUND TO THE STUDY}

Academic performance is significant in measurement and evaluation of how students are successful in educational programmes. The performance is mainly determined by the outcomes in examinations undertaken in schools. The outcome may not be the most feasible means of inference on the students' cognitive ability but it remains the most used where students are taken through various assessments culminating in the final national examination. Studies in the developed countries have been carried out to explore and examine the factors that affect student's academic performance. As reported by Hanson (2000), Student performance is affected by learning abilities, gender and race and also by Simmons, Musoba and Choong (2005) that attending full time, family income level, receiving grant aid and completing advanced level classes in high school have statistically significant effects on college persistence among first generation college students leading to good performance.

Despite many students gaining access to institutions of higher learning over the past decade, there are many different circumstances which have affected the performance and success of students. Based on study by Patino-Pena and Cardona (2013), among the factors that affect the performance of many college students are mainly family socio-economic and high school academic performance. Okioga (2013) surveyed 186 college student to find out what influences academic performance. The outcome showed that students' socio-economic background influences academic performance. The findings showed that families with low income do not take an active role during their children's education resulting to some uneasiness in the day to day life of the students thus influencing them to perform poorly since they do not have adequate study facilities at home and supervision.

Poor students' academic performance is an important issue of concern all over the countries of the world. In the United States of America, it was reported by McWilliams (2015) that although the government had taken many steps and education reforms many students still continue to perform poorly academically. The findings in the same study reported that among the many factors that influence students' academic performance include the students' belief systems, relationship with teachers and peers and classroom management. On the same issue of academic performance another study by Obrentz (2012) asserted that even though there have been many studies on academic performance for decades, the factors which predict academic performance should be studied continuously due to the changing nature of the student's population, the curriculum, use of modern technology and the measure for academic success which may differ from institution to another. P'Pool (2012) asserted the importance of researchers in identifying the specific factors that contribute to students' academic performance so to be able to give a helping hand to educators to develop and use effective teaching methods which could enhance academic performance in all institutions.

Mackenzie and Schweitzer (2001) conducted a study in Australia to examine the psychosocial, cognitive, and demographic predictors of academic performance of first year university students. The findings demonstrated that previous academic performance was identified as the most significant predictors of university performance; other predictors were Integration into university, self-efficacy, and employment responsibilities. Mushtaq and Khan (2012) carried out a study in Pakistan and brought forwarded the argument that, social and economic development of any country is directly linked to the students' academic performance at whatever level. Communication, learning facilities and family related stress were key in affecting students' academic performance

Hijazi and Naqvi (2006) found out that the main factors which affect college students' performance were time allocation for studies, parent's level of income mother's age, attitude towards studies, and mother's education

Teachers in all academic fields were considered as the best determinants of factors for the success of all strategies aimed at developing a descent quality education. Teacher education is considered as very crucial component of education as teachers are considered as mentors of the learners and society at large Teacher education is designed to develop and administer to produce school teachers for the countries established system of education (Kafu,2003). In Kenya research indicates that a variety of factors affect students" academic achievement. Such factors are either contextual personal, or psychological Some studies tend to consider students" academic achievement as an outcome related of contextual factors like school and family factors Kariuki, 2017). More studies have examined how academic achievement is influenced by personal and psychological factors. These include: academic selfconcept (Kwena, 2007); self-regulated learning (Mutweleli, 2014); academic resilience (Mwangi, 2015); self-esteem (Mburung"a, 2016)); and academic mind-set (Mutua 2018). An important issue in Kenya education is the relatively high poor academic performance in Primary Teacher Training colleges which shows skewed trend towards the lower grades .Over the years a worrying trend has been observed in 
the consistent decline in examination performance among students in Teacher Colleges which has affected general performance in Primary Teacher Education Examinations (PTE) .It is evident that studies have been carried out on the constructs of academic selfefficacy, stress and coping strategies outside Kenya but as combined variables and how they affect academic performance on the Kenya experience it has not been done, therefore necessitating the need for the researcher to embark on current study.

Coping can be defined as "the person's cognitive and behavioural efforts to manage (reduce, minimize, master, or tolerate) the internal and external demands of the person and environment transaction that is appraised as taxing or exceeding the person's resources" Folkman, Lazarus, (1986). It involves cognitive and behavioural efforts utilized to manage the internal and external determinants of stress (Lazarus \& Folkman (1984) defines Coping strategies as adaptive or maladaptive (helpful or harmful outcomes.)

Coping strategies are categorized as problemfocused and emotion-focused. Problem-focused entails strategies to modify the given problem at hand by generating options to solve the problem, While Emotion-focused, involves learning how to manage an individual's emotional distress that is specifically related to the situation endler and Parker (1990a, 1990b, 1994) have used a different approach of distinquishing the different type of coping but still anchoring on Lazarus and Folkman strategies of problem focused and emotion focused coping. They have differentiated coping into three factors to develop the 'Coping Instrument for stressful Situations which presents coping as consisting three basic strategic dimension or factors namely, task oriented coping, emotion oriented coping and avoidance oriented coping. The first two factors are similar to the problem focused and emotion focused coping strategies as proposed by Lazarus and Folkman (1984). The avoidance factor has been brought in and incorporated based on empirical evidence that showed that people use avoidance when faced by stressful situations by employing and making use of the social networks around them either positively or negatively. According to Endler and Parker (1990a, 1994), the avoidance oriented coping style may be used by making use of the social networks.

The relationship between stress coping skills and Grade Point Average (GPA) was not very strong Khan (2013). This is contrary to the results of the study by (Kadhiravan \& Kumar, 2012) which discovered that coping strategies can help undergraduate students to enhance their academic performance also supported by Aun, Hern and Ahmad (2011) who had the opinion that coping skills improves class participation class attendance, and persistence even when faced with setbacks or failure in general, and arms the students with stronger more resilient self who can lead to a much more positive learning experience. Active coping fully mediated the relationship between academic stress and school adjustment for gifted high school students Park, Kwon (2014 ). Similarly, Sullivan (2010) proved that academic coping strategies assisted undergraduate students to perform in their academic through academic coping strategies factors like approach, avoidance, and social support,

The purpose of this study was to establish the extent to which coping strategies predict academic performance among students in Teacher Training Colleges in Central region in Kenya.The objectives of the study were,

i. Determine the relationship between coping strategies and academic performance

ii. Establish the extent to which coping strategies predict academic performance

The following two hypotheses were tested

$\mathrm{Ho}_{1}$ There is no significant relationship between coping strategies and academic performance

$\mathrm{Ho}_{2}$ There is no significant predictive power between coping strategies and academic performance.

\section{THEORETICAL FRAME WORK Transactional theory}

The study was guided by the transactional theory by Lazarus and Folkman (1991 This Theory identifies stress as a transaction between individual students and their environment, where the individuals 'students' perception of the stressful situation is the mediating variable of how they are able to cope with it. The relationship between the student and the college environment is emphasized, the relationship is the transaction. Transactions that are perceived as stressful (i.e. harmful, threatening, or challenging) require coping that will manage their level of distress (emotion-focused coping) or manage the problem that is causing their distress (problem-focused coping) Lazarus and Folkman (1991). Problem focused coping changes the student environment relationship by acting on the environment or on the self. Emotion-focused coping is either to change the way the stressful environment is attended to or the relational meaning of what is happening without changing the actual conditions of the relationship.

Coping is an on-going cognitive and behavioural efforts to manage specific external and internal demands that are appraised as taxing or exceeding the 
resources of the student which may hamper performance Lazarus (1993). In the current research the application of transactional theory is appropriate in which appraisal processes and coping will lay a major emphasis in explaining the students' responses and how they will influence performance. The success or no success of coping subsequently will influence the student's academic performance.

\section{REVIEW OF RELATED LITERATURE}

College going students are prone to exposure to considerable amount of stress which call for ever changing successful coping strategies. Stressors are of diverse type and may include pressure from both external and internal sources as seen in the review on stress and academic performance. Coping comes in handy when faced with stress and it will depend on the student's perception and intensity of what is causing the stress. Infective coping can lead to anxiety, drinking problems, depression and other related mental health problems among the students. Many researches have for years looked at college student's response to stress. When stress becomes elevated in the life of a students it calls for coping strategies which will dictate the type of coping strategy and how it may impact on academic performance.

Negotiating a way to make adjustment to the demands of college life may be a source of stress, which can negatively affect motivation and achievement of students Pritchard \& Wilson (2003). Coping strategies, defined as "conscious self-willed efforts to regulate emotion, cognition, behaviour, physiology, and the environment in response to stressful events or circumstances" (Compas, ConnorSmith, Saltzman, 2012) Lazarus \& Folkman (1991), these have been categorized in to two major ones namely Problem-focused coping strategies refer to active efforts to change the problem situation in an effort to reduce the stress associated with it, and emotion-focused coping strategies involving an attempt to change the emotions associated with the stressor, with no direct attempt to change the stressor itself.

Devonport and Lane (2006), reported that coping could influence academic success because the amount of effort students invests to reach a certain outcome is dependent on how they cope with the negative emotions and obstacles. That level of effort and the way students cope with stress is also influenced by their beliefs in themselves on how capable they are and how much control they have over the outcome and academic engagements and academic success. The research evaluated the relationship between coping strategies, work engagement and academic performance. Academic performance was evaluated by the grade point average that adaptive coping and academic engagement and academic performance was positively correlated. Maladaptive coping was negatively related to performance, but there were no significant correlations between maladaptive coping and any academic engagement dimension. Another study was carried out in an Australian University using quantitative approach to identify the challenges facing distance education students and their relative levels of satisfaction, coping and academic performance on 295 students, 64 males and 231 females. The finding showed that there was no clear connection on the use of coping strategy and academic performance.

Task oriented coping strategy is a classified under problem focused copiing.it attempts to solve or limit the impact of the stressful situation. It involves the person affected by the stress taking direct action to alter the situation and reduce the amount of stress it carried. Emotion oriented coping works at limiting the emotional impact of stress instead of solving the situation which is bringing stress. Students who use emotion oriented coping usually directs all efforts by altering the emotional responses to stressors. Reframing or putting it in a different form the problem causing stress to make it inactive in evoking a negative emotional response and elicits less stress Mattlin (1990).

Avoidance oriented coping strategy uses distraction and diversion unrelated to the stressful situation to reduce the stress. It encompasses strategies like avoiding the situation, denying its existence, or losing hope Lazarus \& Folkman (1984). Avoidance oriented coping strategies are usually characterised by the absence of any use of any attempts to try and alter the situation. Okoro (2018) evaluated the issues related to stress and tactics for dealing with stress among undergraduates.

A study carried out by Causey \& Dubow, (1993) to investigate the use of the coping strategies among university students using the Pearson Product Moment Correlation Coefficient in analysis of the relationships, found out that coping strategies were significantly related to perceived academic stress hence academic performance. The correlation was noted on perceived academic stress with task-oriented coping which had a significant negative correlation $(r=-0.16, p<0.05)$, while with emotion-oriented coping was significantly positively $(\mathrm{r}=0.20, \mathrm{p}<0.01)$. Avoidance was also positively correlated with academic stress even though as noted it was not significant. The findings informed that students experiencing academic stress utilize mainly emotion and oriented coping strategies Task oriented coping strategy minimally correlated with academic stress. On the other Task oriented coping was 
the most commonly used coping method followed by avoidance and then emotion oriented strategy among the students of both years. No significant difference was observed among avoidance oriented and emotion oriented strategy between the first and third year students. emotion-oriented mean coping scores among the respondents Item Emotion-oriented coping items First Year Third Year Male Female. Based on the review there are inconsistencies in different research findings which the researcher need to unravel and also most of the findings seem to be in developed counties thus a study to get the Kenyan experience is appropriate.

\section{RESEARCH DESIGN AND METHODOLOGY}

The study adopted a descriptive survey design coping strategies and how they relate with academic performance. descriptive survey design is used to describe the characteristics of the sample population through observation, description and analysis of the population and Survey research design is used to get opinions of the respondents. interviews were conducted on participants selected randomly from the academic departments in order to get experienced personal perspectives of the students' participants regarding coping strategies.

\section{Research Instrument}

The coping inventory used for the study was the adapted from (CISS-SF Coping Inventory for Stressful Situations-CISS21 by Endler and Parker (1999)The CISS has three subscales or coping types: task oriented, emotion oriented and avoidance oriented The Likert scale was rated on a five-point scale and the responses range from 5 (almost always) 1 (almost never) The responses on all the 7 items of each subscale in the CISS-21 were summed together to obtain aggregate scores for the three coping strategies. The dominant style of each individual was determined by his/ her score in each of the triple dimensions of coping styles.

\section{Reliability}

Cronbach's alpha coefficients for the task oriented was 0.69 against the original 0.831 for the emotion oriented was 0.84 against the original 0.781 and lastly for the avoidance it was 0.79 against the original 0.73. thus the scales were deemed fit for use.

\section{Data Analysis Procedures}

All the statistical analyses were run using the Statistical Package for Social Science (SPSS) version 26 computer programme. Pearson Product Moment Correlation Coefficient to test the relationships between the dependent variable and the independent variables, while Regression analysis was used to measure the strength of the relationships.

\section{RESEARCH FINDINGS}

The participants' level of coping strategies was presented in table 1

Table 1: Levels of Coping Strategies

\begin{tabular}{ccc}
\hline Level of coping strategies & Frequency & Percent \\
\hline Low (21-49) & 0 & 0.0 \\
Average $(50-76)$ & 197 & 100.0 \\
High (77-105) & 0 & 0.0 \\
\hline Total & 197 & 100.0 \\
\hline
\end{tabular}

All the participants rated themselves within the average category when all the coping strategies are combined making $100 \%$, That means the students were not low in the use of coping strategies neither did they rate themselves too high. Since coping strategies had three categories, the students total scores in the categories was presented in order to find out how each category rated in the three strategies as shown in table 2.

Table 2: Descriptive statistics of the sub scales of Coping Strategies

\begin{tabular}{ccccccc}
\hline & \multicolumn{2}{c}{ Task Oriented } & \multicolumn{2}{c}{ Emotion Oriented } & \multicolumn{2}{c}{ Avoidance Oriented } \\
\hline Rating & Frequency & Percent & Frequency & Percent & Frequency & Percent \\
\hline Low (7-16) & 0 & 0.0 & 30 & 15.2 & 16 & 8.1 \\
Average (17-25) & 134 & 68.0 & 167 & 84.8 & 181 & 91.9 \\
High (26-35) & 63 & 32.0 & 0 & 0.0 & 0 & 0.0 \\
\hline Total & $\mathbf{1 9 7}$ & $\mathbf{1 0 0 . 0}$ & $\mathbf{1 9 7}$ & $\mathbf{1 0 0 . 0}$ & $\mathbf{1 9 7}$ & $\mathbf{1 0 0 . 0}$ \\
\hline Table shows that $68 \%$ of the participants in the & \multicolumn{2}{c}{ rated themselves high. On emotion oriented coping } \\
task oriented coping rated themselves average and 32\% & $84.8 \%$ rated themselves average and 15.2 low while
\end{tabular}


avoidance was $91 \%$ average and $8.1 \%$ low. In all the groups the average category was rated highly.

\section{HYPOTHESIS TESTING}

To test the hypothesis, a bivariate correlation analysis was performed by computing the Pearson product moment correlation The results showed that there was significant negative relationship between coping strategies and academic performance $(r=0 .-5 \mathrm{p}$ $<0.01)$ the null hypothesis was therefore rejected. That implied that the more the students used the coping strategies the less they performed

Table3 Hypothesis Testing between Coping Strategies and Academic Performance ( $=197)$

\begin{tabular}{lll}
\hline & \multicolumn{2}{c}{ Academic Performance } \\
\hline Coping Strategies & Pearson correlation & \multicolumn{1}{c}{$-.56^{* *}$} \\
& Sig (tailed) & .000 \\
$\mathrm{~N}$ & 197 \\
\hline
\end{tabular}

${ }^{* *}$ Correlation significant at $\mathrm{P}<0.01$ level ( 2 tailed)

Further analysis was done to test the relationship of subscales of coping strategies with academic performance

Table 4: Hypothesis testing for the Subscales of Coping Strategies and Academic performance

\begin{tabular}{llll}
\hline & & $\begin{array}{l}\text { Academic } \\
\text { score }\end{array}$ & $\begin{array}{c}\text { performance } \\
\text { Sig(2 tailed) }\end{array}$ \\
\hline Task oriented & Pearson (2 tailed) & $.68^{* *}$ & .000 \\
Emotion oriented & Sig & & $.75^{* *}$ \\
Avoidance oriented & Pearson (2 tailed) & & .000 \\
& sig & $-.68^{* *}$ & .000 \\
\hline
\end{tabular}

$* *$ Significant at $\mathrm{p}<0.01$

Observation show that, there was a significant positive relationship between task oriented coping and academic performance $(\mathrm{r}=0.68, \mathrm{p}<0.01)$ thus the supplementary null hypothesis was rejected. It was therefore concluded that the use of task oriented coping leads to high academic performance. There was a significant negative relationship between emotion oriented coping and academic performance ( $\mathrm{r}=0 .-75$, $\mathrm{p}<0.01$ ), thus the second supplementary null hypothesis was rejected and a conclusion was made that the use of emotion oriented coping by the participants led to low performance. Lastly there was a significant negative relationship between avoidance oriented coping and academic performance $(r=0-.68$, $\mathrm{p}<0.01$ ), thus the null supplementary hypothesis was rejected and a conclusion made that participants use of avoidance coping led to low academic performance.

\section{Regression Analysis}

The researcher performed Multiple regression analysis of the students' coping strategies and the subscales in order to find out to what extent the students coping strategies predict academic performance as shown in table 5

Table 5: Regression analysis of Coping Strategies and Academic Performance

\begin{tabular}{llllll}
\hline Model & Sum of squares & df & Mean squares & F & Sig \\
\hline Regression & 6176.447 & 1 & 6276.447 & 89.732 & .000 \\
Residual & 13423.554 & 195 & 68.839 & & \\
\hline Total & $\mathbf{1 9 6 0 0 . 0 0 1}$ & $\mathbf{1 9 6}$ & & & \\
\hline
\end{tabular}

Dependent-academic performance, Independent-coping strategies

As shown in table 5 students coping strategies were a significant predictor of academic performance (F 1195
$=89.5, \mathrm{p}<0.05)$ therefore the null hypothesis was rejected 
The researcher sought to establish the individual subscales of the students coping strategies prediction on academic performance as presented in table 6

Table 6: Regression Analysis of the Subscales of Students Coping Strategies on Performance

\begin{tabular}{|c|c|c|c|c|c|c|c|c|c|}
\hline \multirow{3}{*}{$\begin{array}{l}\text { Model } \\
1\end{array}$} & \multicolumn{3}{|c|}{ Sum of Squares df } & \multicolumn{2}{|c|}{ Mean Square } & Adj $R^{2}$ & \multirow{2}{*}{$\begin{array}{l}\mathbf{F} \\
0.59\end{array}$} & Sig. & \multirow[b]{2}{*}{.000} \\
\hline & Regression & & 728 & 3 & 3913.909 & & & 96.126 & \\
\hline & Residual & & & 193 & 40.716 & & & & \\
\hline & Total & 001 & 19 & & & & & & \\
\hline
\end{tabular}

The results in table 6 showed that the subscales of students coping strategies were significant predictors of academic performance $(\mathrm{F} \mathrm{3,193)}=96.12, \mathrm{p}<0,05$. The coefficient of determination $\mathrm{R}^{2}=.59$ meant that the subscales of students coping strategies explained $59 \%$ of the variation in academic performance. Based on the findings an analysis to determine the predictive weight of the subscales of coping strategies on academic performance. The results are shown in table 7

Table7: Predictive weight of students Coping Strategies subscales on Academic Performance

\begin{tabular}{cccccc}
\hline Model & $\begin{array}{c}\text { Unstandardized } \\
\text { B }\end{array}$ & $\begin{array}{c}\text { coefficient } \\
\text { Std error }\end{array}$ & $\begin{array}{c}\text { Standardized } \\
\text { Beta }\end{array}$ & t & Sign \\
\hline Constant & 59.86 & 10.0 & & 5.966 & .000 \\
Task & .831 & .229 & .260 & 3.966 & .000 \\
Emotion & -1.546 & .320 & -.501 & -4.828 & .000 \\
Avoidance & -211 & .328 & -.062 & -643 & .521 \\
\hline
\end{tabular}

The findings in table 8 showed that the best significant predictor of academic performance was task oriented coping identified as $(\beta=0.26, p<0.05)$. Emotion oriented negatively significantly predicted academic performance at $(\beta=-0.50, \mathrm{p},<0.05)$ while avoidance negatively insignificantly prediction at $(\beta=-$ $0.06, \mathrm{p},>0.05)$. Therefore the following prediction model was illustrated,

$\breve{y}=59.86-0.50(\mathrm{EOC})-0,06(\mathrm{AOC})+0.26(\mathrm{TOC})\left(\mathrm{R}^{2}=59\right)$, $\mathrm{p}<0,05$

Therefore, students coping strategies had a significant prediction on academic performance and the subscales both task oriented and emotion oriented had significant predictive weight on academic performance while avoidance oriented coping had an insignificant prediction.

\section{DISCUSSION OF THE FINDINGS}

On the overall. The study findings revealed a significant relationship between coping strategies and academic performance and that coping strategies predicted academic performance. This outcome was supported by Gustems et al (2019) who examined stress in teacher education students and found out that many students experienced stress and used avoidance coping strategies. The students who were under less stress and engaged less in cognitive avoidance and more in problem-focused coping (task oriented) were also the students who made more academic achievement; and students under more stress performed worse. Devonport and Lane (2006) reported that coping could influence academic success because the level of effort students invested to reach a certain outcome dependent on how they coped with the negative emotions and obstacles. That level of effort and the way students coped with stress was also influenced by their beliefs in themselves on how capable they were and how much control they had over the outcome and academic engagements and academic success. Adaptive coping and academic engagement and academic performance was positively correlated and maladaptive coping was negatively correlated with academic performance. Alberto D. (1999) showed that each of the dimensions of coping strategy was positively and significantly related to student's general weighted average and was concluded that the more adaptive and tolerable the students to academic and personal stress, the better their academic performance.

\section{CONCLUSION}

On the overall. The findings of the study revealed a negative significant relationship between the students coping strategies and academic performance. Task oriented coping strategy had a positive significant relationship with academic performance while both emotion and avoidance coping strategies had a negative significant relationship with academic performance. Students coping strategies were a significant predictor 
of academic performance while the subscales of task oriented and emotion oriented were also significant predictors of academic performance. Avoidance oriented coping was found to be an insignificant predictor of academic performance. Therefore, it was concluded that stress coping strategies affects students' academic performance in primary teacher training colleges in central region and that means students should be properly guided on how to respond to stressful situations in order to be able to achieve their academic goals in the stipulated time frame.

\section{RECOMMENDATIONS}

Stakeholder should design programmes to teach students to use positive coping strategies more frequently to help buffer the negative impact of stress on academic performance. There is need to provide adequate guidance and counselling in order to decrease psychological and social stress. The colleges should also step out to reduce students stress for proper mental health and ability to perform well in their studies through engaging competent and trained counsellors to help student on how to negotiate and counter the effects of stress.

\section{REFERENCES}

1. Alberto D, Karen A, John B (2018) Coping mechanism and academic performance among Filipino undergraduate's students. KnE Social Sciences /4th International Research Conference on Higher Education / Pages 30-42

2. Aun, W., Kimura, L., Hern, C. and Ahmad, S. (2011), "Psychological Factors in Academic Performance among College Students", 3rd International Conference on Teaching and Learning, Park royal Penang, Penang, Malaysia.

3. Babar, Nawaz, Khan \& Khan (2004) Students, Stress and Coping Strategies: A Case of Pakistani Medical. Education for Health 17(3):346-53 .

4. Bamuhair, S. S., Al Farhan, A. I., Althubaiti, A., Agha, S., Rahman, S., \& Ibrahim, N. O. (2015). Sources of stress and coping strategies among undergraduate medical students enrolled in a problem-based curriculum. Depression, 20, 33

5. Bouteyre, E., Maurel, M, \& Bernaud1, J. (2007). Daily hassles and depressive symptoms among first year psychology students in France: the role of coping and social support. Stress and Health, 23, 93-99.

6. Causey, D. L., \& Dubow, E. F. (1993). Negotiating the transition to junior high school: The contributions of coping strategies and perceptions of the school environment. Prevention in Human Services, 10, 59-81

7. Compas, B. E., Connor-Smith, J. K., Saltzman, H., Thomsen, A. H., and Wadsworth, M. E. (2001).
Coping with stress during childhood and adolescence: problems, progress, and potential in theory and research. Psychol. Bull. 127, 87-127. doi: 10.1037/0033-2909.127.1.87

8. Devonport, T. J. \& Lane, A. M. (2006). Relationships between self-efficacy, coping and student retention. Social Behavior and Personality, 34 pp127-138.

9. Endler NS, Parker JDA. Coping Inventory for Stressful Situations (CISS): Manual. Second ed., Toronto: Multi-Health Systems, 1999

10. Gustems, J., Calderon, C. (2013) Coping strategies and psychological well-being among teacher education students. European Journal of Psychology of Education 28(4): 1127-1140. Google Scholar

11. Hanson, J.B. (2000). Student performance and student growth as measures of success: An evaluator's perspective. Paper presented at annual meeting of the American Educational research association New Orleans. Louisiana. 25 April

12. Hijazi, S.T. and Naqvi, S.M.M.R. (2006). Factor Affecting Students' Performance: A case of Private Colleges. Bangladesh e-journal of Sociology, 3(1).

13. Higgins, J. E. \& Endler, N. (1995). Coping, life stress, and psychological and somatic distress. European Journal of Personality, 9, 253-270.

14. Kafu, P.A. (2003). Teacher Education: Its implications to quality of Teachers in Kenya (Unpublished paper). Moi University

15. Kadhiravan, S., \& Kumar, K. (2012). Enhancing stress coping skills among college students. Journal of Arts, Science \& Commerce, 3(4), 4955. doi: Retrivied from

16. http://www.researchersworld.com/vol3/issue4/vol 3_issue4_1/Paper_07.pdf

17. Kariuki, D.G. (2017). Personal, family and school factors as correlates of Achievement Motivation among form two students in Nairobi County Kenya. (Unpublished doctoral dissertation). Kenyatta University, Nairobi, Kenya)

18. Kwena, J. S. A. (2007). An investigation into selected factors on academic self-concept among primary school pupils in Bondo District. (Unpublished doctoral thesis). Kenyatta University, Nairobi, Kenya

19. Lazarus, R. (1999). Stress and Emotion: A New Synthesis. London: Free Association Books. R.S. Lazarus. ISBN 1-85343-456-6.

20. Lazarus, R., Folkman, S. (1984). Stress, Appraisal and Coping. New York: Springer.

21. Mathew, C. P. (2017). Stress and coping strategies among college students. IOSR Journal of Humanities and Social Science (IOSR-JHSS), 22(8), 40-44. [Google Scholar

22. Mathew, B and Jayan, C. (2006). Academic Stress and Coping Styles among Plus-two Students. Indian Psychological Review, 66

23. Mattlin, J. A., Wethington, E., \& Kessler, R. C. (1990). Situational determinants of coping and 
coping effectiveness. Journal of Health and Social Behavior, $31(1)$, $103-$ 122. https://doi.org/10.2307/2137048

24. Mburung'a, R. N. (2016). Students' and teachers' retention perception as predictors of self- esteem and academic achievement in secondary schools in Meru County, Kenya. (Unpublished doctoral dissertation). Kenyatta University, Nairobi, Kenya

25. Marzano, R.J. \& Pickering, J.D. (2006). Classroom management that work. Research based strategies for every teacher. Alexandria: Association for supervisors and curriculum

26. McKenzie, K. (1999). Correlation between Selfefficacy and Self-esteem in students. Retrieved $18 / 2 / 2019$

27. Mutua, J.N. (2018). Academic Mindsets as Predictors of Academic Achievement among Public Secondary School Students in Nairobi County, Kenya. (Unpublished doctoral dissertation). Kenyatta University, Nairobi, Kenya

28. Mutweleli, S.M. (2014). Academic motivation and self-regulated learning as predictors of academic achievement of students in public secondary schools in Nairobi County, Kenya. (Unpublished doctoral dissertation). Kenyatta University, Nairobi,

29. Mushtaq, I., \& Khan, S.N. (2012). Factors affecting students" academic performance. Global Journal of Management and Business Research, 12(9). Retrieved from http://creativecommons .org/licenses/by- nc/3.0/

30. Mwangi, C. (2015). Predictors of academic resilience and its relationship to academic achievement among secondary school students in Kiambu county, Kenya. (Unpublished doctoral dissertation). Kenyatta University, Nairobi, Kenya

31. Obrentz, S. B. (2012). "Predictors of Science Success: The Impact of Motivation and Learning strategies on College Chemistry Performance." Educational Psychology and Special Education Dissertations.Paper77. Retrieved from http://scholars.gsu.edu/epse_diss

32. Okioga, C.K., (2013). The impact of students' socioeconomic background on academic performance in universities, a case of students in Kisii University College. American International Journal of Social Science, Vol. 2 (2), 38-46

33. Okoro, E. (2018). Assessment of stress related issues \& coping mechanisms among college students (Unpublished Maters Thesis). Minnesota State University, Mankato, Minnesota. [Google Scholarl

34. P'Pool, K. (2012). Using Dweck's theory of motivation to determine how student's view of intelligence affects their overall academic 172 achievement. (Master"s thesis). Retrieved from http://digitalcommons.wku.edu/thesis/1214

35. Patiño Peña, L., and Cardona, A. (2013). Review of some studies on university student dropout in
Colombia and Latin America. Acta Universitaria, Vol. 23(4), 37-46.

36. http://shodhganga.inflibnet.ac.in/handle/10603/809 3 on March 3, 2018

37. Park. M. Kwon Y., \& Shin, H. (2014). Coping strategies as a mediator between gifted students academic stress and school adjustment. Korea Youth Research, 21(8), pp1-25

38. Pritchard, M. E., Wilson, G., \& Yamnitz, B. (2004). What predicts adjustment among

39. college students? A Longitudinal Panel Study

40. Shaikh, B. T., Kahloon, A., Kazmi, M., Khalid, H., Nawaz, K., Khan, N. A., \& Khan, S. (2004). Students, stress and coping strategies: A case of Pakistani medical school. Education for Health, 17, 346-353

41. Sullivan, J. (2010), "Preliminary Psychometric Data for the Academic Coping Strategies Scale”, Assessment for Effective Intervention, Vol. 35, No. 2, Pp. 114- 127.

42. Simmons, A.B., Musoba, G.D. and Choong, C.G. (2005). Persistence among First Generation College Students in Indiana: The Impact of Precollege Preparation, College Experiences, and Financial Aid. Indian Project on Academic Success (IPAS) Research Report \# 05-01 